\title{
Study on the Structure Transition of Graphite And Quartz Doped with Silicon under High Temperature and High Pressure
}

\author{
Dejun Wang ${ }^{\mathrm{a}}$, Runru Liu ${ }^{\mathrm{b}}$, Leng Jing ${ }^{\mathrm{c}^{*}}$, Lili Wang ${ }^{\mathrm{b}}$, Xinyu Bai ${ }^{\mathrm{d}}$ \\ ${ }^{\mathrm{a} C}$ College of Continuing Education, Changchun University, Changchun 130022.P.R.China \\ ${ }^{b}$ College of Science, Changchun University, Changchun 130022. P.R. China \\ ${ }^{\mathrm{c}}$ School of Basic Sciences, Changchun University of Technology, Changchun 130012.P.R.China \\ ${ }^{\mathrm{d}}$ Jilin Science and Technology Museum, Changchun 130117.P.R.China
}

\begin{abstract}
A new laboratory method has been suggested for synthesizing coesite in the Earth's crust by considering the similar characteristics of local collisions and shearing strength between the earth's plates and the high-energy mechanical ball milling (MBM),combining the high static pressure and high temperature technique, and using the mixtures of $\alpha$-quartz and graphite as the initial materials, in which Silicon is mixed by the best quality ratio. The lowest pressure and temperature condition for synthesizing coesite is $3.8 \mathrm{GPa}$ and $873 \mathrm{~K}$.
\end{abstract}

Keywords- $\alpha$-quartz-graphite ; Coesite; High temperature and high pressure.

\section{INTRODUCTION}

Quartz is a very common natural mineral and can form a number of different variants of the structure under different temperature and pressure conditions. According to the quartz variant the surrounding environment pressure and temperature can be qualitatively estimated in the Geology. Coesite is the UHP variant of the quartz and a kind of effective minerals indicating the pressure. In the nature, graphite and quartz are sometimes born in natural minerals and another kind of UHP variant of the graphite - diamond is the minerals indicating higher pressure. Among the rocks on the earth surface diamond has been found in the form of associated with the coesite or inclusions. To explain the existence of coesite on the earth surface and at the same time to confirm whether or not accompanied by the diamond produced in the process of their formation and the existence of the mutual influence, we used high-energy mechanical ball milling combining the high static pressure and high temperature method to simulate the formation mechanism of coesite and diamond in the Earth's surface by considering the similarity of local collisions and shear stress between the earth plate collision and the high-energy mechanical ball milling (MBM).

We concluded that the longer the milling time, the smaller the sample size, the better the effect of amorphous and the easier the synthesis of coesite and diamond. However, the amorphous of graphite is one of the difficulties in the work. Graphite and $\alpha$-quartz mixed powder can be close to completely amorphous after milling $120 \mathrm{~h}$. According to the literature [1] reported that graphite amorphous time can be greatly shortened by adding silicon in graphite and $\alpha$-quartz mixtures, the time of the best quality is the ratio of $\mathrm{Si}: \mathrm{C}: \mathrm{SiO}_{2}=65: 14: 21$. So in order to improve the amorphous graphite, Silicon is joined into the $\alpha$-quartz powder mixed with graphite. While the silicon content in the earth ranks second and the $65 \%$ of the silicon in such mixtures enables the ratio of silicon and carbon to be closer to the real situation in the Earth's interior and to simulate changes of the structure of the material in the Earth realistically. This can provide experimental basis for the research on the mineralization condition of coesite in the Earth surface and Ultra High-pressure (UHP) metamorphism and artificial simulation of the symbiotic of diamond and coesite under higher pressure.

\section{EXPERIMENTAL}

The initial $\alpha$-quartz powder has a purity of $99.9 \%$ and its grain size is less than $600 \mathrm{~nm}$. Graphite powder has a chemical purity and grain size less than $30 \mu \mathrm{m}$.

A GN-2 type vibrating mechanical ball mill with highenergy; A belt-type two-anvil press of 500t; The Rigaku D/Max-rA $12 \mathrm{~kW}$ x-ray diffractometer (XRD) was used to record the XRD patterns with $\mathrm{Cu}$ radiation and the XPS spectra was obtained using VG ESCALAB Mark II system. JY-HR 800 high-resolution Raman spectroscope and H8100IV TEM system were used respectively in the experiment for the characterization analysis.

\section{RESULTS AND DISCUSSION}

A. The amorphous and Characterization of samples under high-energy mechanical milling condition

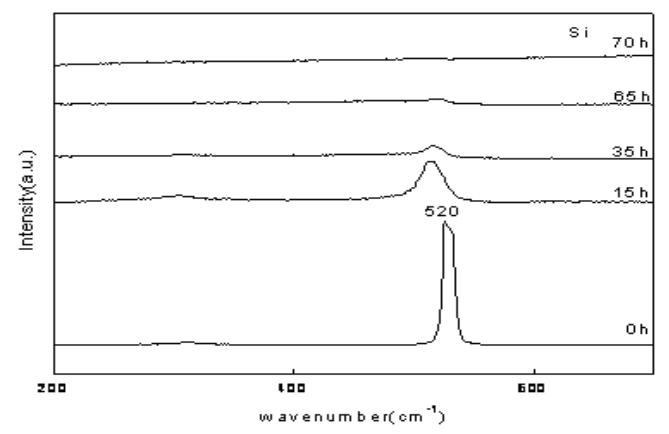

Figure 1. The Raman spectra of silicon powder after milling $0 \mathrm{~h}, 15 \mathrm{~h}, 35 \mathrm{~h}$, $65 \mathrm{~h}, 70 \mathrm{~h}$ respectively.

Figure 1 shows the Raman spectra of silicon powder by the high-energy mechanical milling after different time. The silicon becomes completely amorphous after $70 \mathrm{~h}$ which is 
longer compared to the time required for quartz and graphite while signally milled separately. This is mainly because the diamond structure of the silicon is relatively stable that can not be easily damaged.

And it can be seen from Figure 2 that the peak of quartz had disappeared after milling $10 \mathrm{~h}$ which implies the completely amorphous of it. After milling $20 \mathrm{~h}$ most of silicon has become amorphous and after milling 40h it becomes completely amorphous characterized by disappearance of the main vibration peak $520 \mathrm{~cm}^{-1}$. Comparing to the ball milling time of $70 \mathrm{~h}$ while individually, the amorphous time is shortened by $30 \mathrm{~h}$.

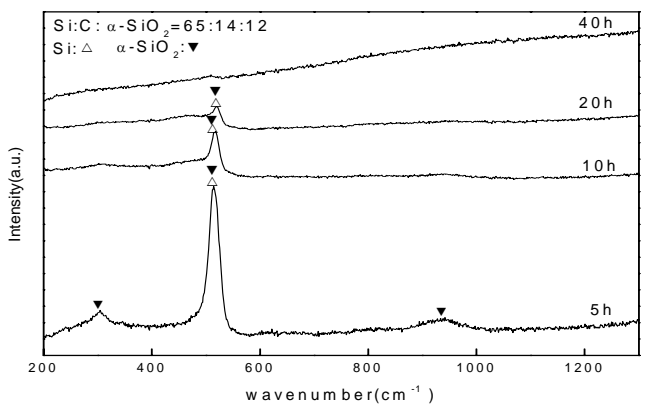

Figure 2. The Raman spectra (wave number range 200-1300cm-1) of $\alpha$ quartz graphite and silicon powder mixture (mixed mass ratio $\mathrm{Si}: \mathrm{C}: \mathrm{SiO} 2$ $=65: 14: 21$ ) by the high-energy mechanical milling after $5 \mathrm{~h}, 10 \mathrm{~h}, 20 \mathrm{~h}, 40 \mathrm{~h}$, respectively.

Figure 3 shows the result of Raman spectra of $\alpha$-quartz, graphite and silicon powder mixture by the high-energy mechanical milling after $5 \mathrm{~h}, 10 \mathrm{~h}, 20 \mathrm{~h}, 40 \mathrm{~h}$, respectively when the mixed mass ratio of $\mathrm{Si}: \mathrm{C}: \mathrm{SiO}_{2}=65: 14: 21$ (wavenumber range $1000-1600 \mathrm{~cm}^{-1}$ ), and we can concluded from it that the characteristic peak of $1582 \mathrm{~cm}^{-1}$ has completely disappeared after milling $5 \mathrm{~h}$ and another characteristic peak of $1338 \mathrm{~cm}^{-1}$ has mostly disappeared which implies the mostly amorphous of it. After milling $10 \mathrm{~h}$ the two main peaks have completely disappeared which applied the completely amorphous of graphite.

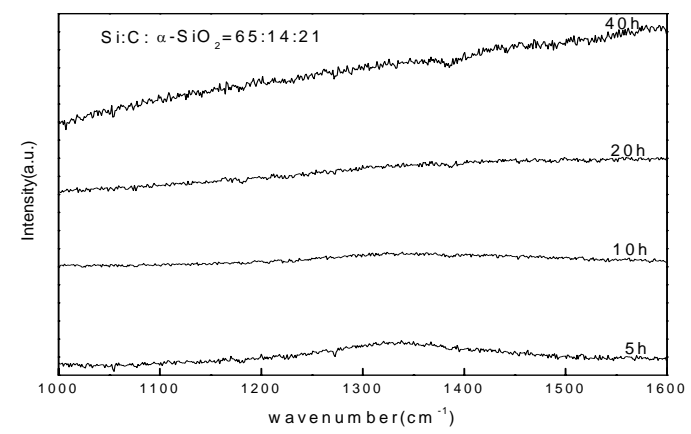

Figure 3. The Raman spectra of $\alpha$-quartz, graphite and silicon powder mixture by the high-energy mechanical milling.
Figure 4 is the XRD patterns of the $\alpha$-quartz, graphite and silicon powder mixture (mixed mass ratio $\mathrm{Si}: \mathrm{C}: \mathrm{SiO}_{2}=$ $65: 14: 21)$ by the high-energy mechanical dealing with milling $5 \mathrm{~h}, 10 \mathrm{~h}, 20 \mathrm{~h}, 40 \mathrm{~h}$, respectively. After milling $20 \mathrm{~h}$ the strongest characteristic peaks of graphite and quartz disappeared which means that the amorphous of graphite and quartz has been formed completely. The peak-311of Silicon has completely disappeared and intensity of 111 and 220 peaks become extremely weak which indicated that most of amorphous has been formed. After milling $40 \mathrm{~h}$ graphite, quartz and silicon have been completely amorphous and $\mathrm{Fe} 3 \mathrm{Si}$ appeared which resulted from the formation of iron and silicon during the process of collision of grinding balls.

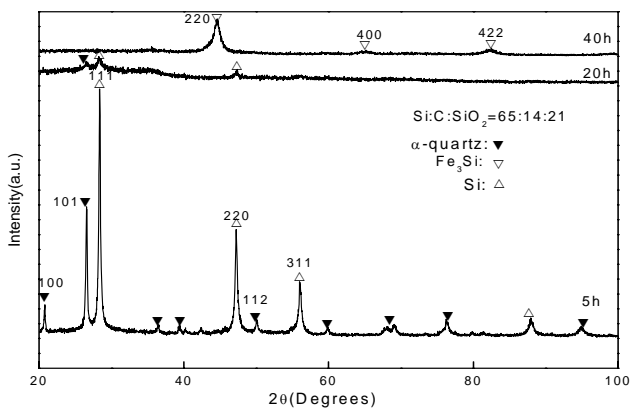

Figure 4. The XRD patterns of $\alpha$-quartz, graphite and silicon powder mixture dealing with the high-energy mechanical milling.

B. The XRD spectra of the milling samples dealing with high-temperature and high-pressure

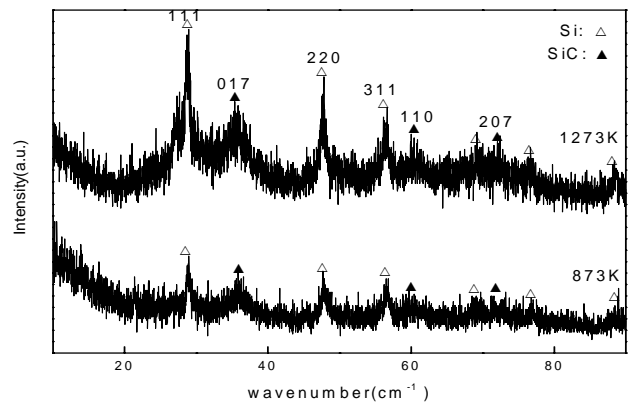

Figure 5. The XRD patterns of samples after milling 20h treated under 2.5GPa, $873 \mathrm{~K}, 1273 \mathrm{~K}$, respectively.

It can be seen from Figure 5 that the silicon crystal and silicon carbide crystals were synthesized when the sample after milling $20 \mathrm{~h}$ was treated under the condition of $2.5 \mathrm{GPa}$, $873 \mathrm{~K}$ and $2.5 \mathrm{GPa}, 1273 \mathrm{~K}[2-6]$, respectively (the keeping time of HPHT is $30 \mathrm{mins}$ ). But the crystallization is not completed which due to the shorter time is kept under the condition of high temperature and high pressure. Under the low pressure conditions, the longer keepings time the better effect. 
Combining Figure 3, 4 and 5 we can conclude that after milling 20h quartz, graphite and silicon has been amorphous basically and after milling $40 \mathrm{~h}$ the three substances have been completely amorphous. And comparing to the two mixture of $\alpha$-quartz and graphite the time of amorphous quartz is longer which is due to the $\alpha$-quartz new phase from the reaction of silicon and oxygen in the air under the high temperature and high pressure formed in the milling process. In this process the amorphous time of graphite has been shortened by nearly $100 \mathrm{~h}$ which indicated that the introduction of the silicon to the graphite is effective for the amorphous.

When the temperature and pressure conditions reached $3.8 \mathrm{GPa}$ and $873 \mathrm{~K}, 1273 \mathrm{~K}$ respectively, not only the silicon crystal but also the SiC crystals and crystal coesite have been synthesized. This due to the formation of silicon carbide crystals from carbon and silicon under the high temperature and high pressure condition and at the same time formed a homogeneous isomer quartz crystal--- coesite.

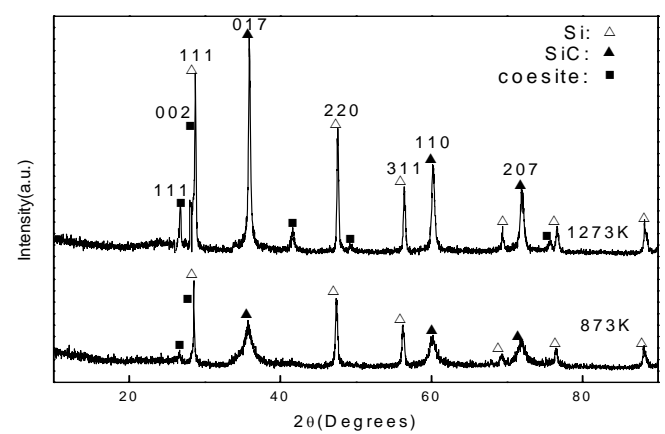

Figure 6. The XRD patterns of samples after milling 20h under 3.8GPa, $873 \mathrm{~K}$, and $1273 \mathrm{~K}$, respectively.

However, we can visible from the pattern that the peak intensity at $3.8 \mathrm{GPa}, 1273 \mathrm{~K}$ is stronger than that at $3.8 \mathrm{GPa}$, $873 \mathrm{~K}$ and especially the peak of coesite not only intensified but also the formation of the peak significantly increased. This indicated that samples after $20 \mathrm{~h}$ milling treated under 3.8GPa pressure conditions, the higher the temperature the more sorts of the crystal formed and more narrow the diffraction peak, and at the same time the peak intensity is stronger, the crystal grain size is greater.

TABLE I. THE GRAIN SIZE OF THE SAMPLES AFTER MILLING 40H AT DIFFERENT TEMPERATURE AND PRESSURE

\begin{tabular}{lcccc}
\hline HKL $(220)$ & $2.5 G P a(873 K)$ & $2.5 G P a(1273 K)$ & $3.8 G P a(873 K)$ & $3.8 G P a(1273 K)$ \\
$2 \theta\left({ }^{0}\right)$ & 44.926 & 45.193 & 44.477 & 44.966 \\
FWHM $\left({ }^{0}\right)$ & 0.741 & 0.511 & 0.478 & 0.459 \\
D $(\mathrm{nm})$ & 0.200 & 0.295 & 0.310 & 0.323 \\
\hline
\end{tabular}

It can be seen from Table 1 that at the same pressure the higher the temperature the larger the grain size and the higher the degree of crystalline of crystal; at the same temperature, the greater the pressure, the smaller the grain size.

Summing up the above, we can see that when silicon is put into a mixture of graphite and quartz the time of amorphous graphite is shortened. Before the silicon is amorphous, silicon, silicon carbide and coesite can be synthesized when the sample was treated under the high temperature and high pressure processing, but after the silicon is amorphous the product of all is only the single phase Fe3Si. So whether or not the silicon is amorphous plays a decisive role on the formation of the crystal products.

\section{CONCLUSIONS}

The amorphous time of graphite is greatly reduced while the crystal structure of coesite does not be affected when silicon is put into $\alpha$-quartz powder and graphite mixture. But whether or not silicon is completely amorphous has a decisive role on the formation of the crystal product. The samples after high-energy ball milling was treated under the high temperature and high pressure conditions. We found that the crystalline silicon and silicon carbide crystals had been synthesized but not coesite when the samples after milling $20 \mathrm{~h}$ was treated under $2.5 \mathrm{GPa}, 873 \mathrm{~K}$, and $2.5 \mathrm{GPa}, 1273 \mathrm{~K}$,respectively. But at $3.8 \mathrm{GPa}, 873 \mathrm{~K}$ and $3.8 \mathrm{GPa}, 1273 \mathrm{~K}$ coesite has been produced accompanied with crystal silicon carbide and silicon crystals. The synthesis temperature of coesite has been dropped and a new phase of the silicon carbide has produced compared to the results of -quartz and graphite mixture.

\section{ACKNOWLEDGEMENTS}

The research work was supported by NCET-13-0697, National Natural Science Foundation of China under Grant No. 51302019, Natural Science Foundation of Qinghai Provincial under Grant No. 20130413047GH, the Research Funds of Industrial Technology Research and Development Projects of Jilin Province under Grant No.JF2013C050-1, Science and Technology Development Program of Changchun City under Grant No. 13GH1land No. $14 \mathrm{KG} 108$, to which we gratefully acknowledged. 


\section{REFERENCES}

[1] GUO. The principle of material structure. High Education Press, (Edition 1st, 460, 1985.

[2] T.V. Torchynska, A. Di'az Cano, S. Jime'nez Sandova, M. Dybic,S. Ostapenko , M. Mynbaeva. Photoluminescence and Raman spectroscopy in porous SiC. Microelectronics Journal 36 , 536-538, 2005.

[3] S. Nakashima, Y. Nakatake, Y. Ishida, T. Talkahashi, H. Okumura. Detection of defects in SiC crystalline films by Raman Scattering. Physica B 308-310, 684-686, 2001.
[4] H. Hobert a,), H.H. Dunken a, J. Meinschien b, H. Stafast. Infrared and Raman spectroscopic investigation of thin films of AIN and SiC on Si substrates. Vibrational Spectroscopy 19, 205-211, 1999.

[5] Sung-Sik Chang, Akira Sakai. Luminescence properties of sparkprocessed SiC. Materials Letters 58, 1212-1217, 2004.

[6] Yanling Ward, Robert J. Young, Robert A. Shatwell. Determination of residual stresses in $\mathrm{SiC}$ monofilament reinforced metal-matrix composites using Raman spectroscopy. Composites: Part A 33, 1409-1416, 